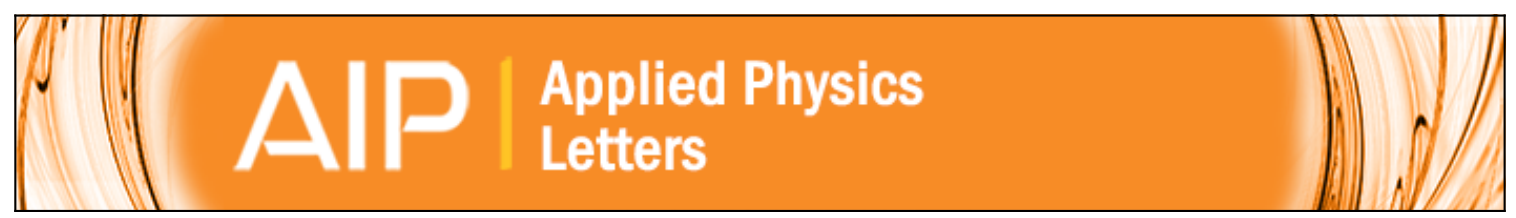

\title{
Mechanism for enhancement of electrical activation of silicon in GaAs by aluminum co-implantation
}

J. P. de Souza and D. K. Sadana

Citation: Applied Physics Letters 63, 3200 (1993); doi: 10.1063/1.110198

View online: http://dx.doi.org/10.1063/1.110198

View Table of Contents: http://scitation.aip.org/content/aip/journal/apl/63/23?ver=pdfcov

Published by the AIP Publishing

\section{Articles you may be interested in}

Electrical behavior of implanted carbon impurities in fluorine co-implanted $\mathrm{GaAs}$

J. Appl. Phys. 80, 3834 (1996); 10.1063/1.363337

Complete p-type activation in vertical-gradient freeze GaAs co-implanted with gallium and carbon

Appl. Phys. Lett. 68, 1537 (1996); 10.1063/1.115691

The effect of coimplantation on the electrical activity of implanted carbon in GaAs

J. Appl. Phys. 74, 7118 (1993); 10.1063/1.355027

High activation efficiency in Mg+ implanted GaAs by $\mathrm{P}+$ coimplantation

Appl. Phys. Lett. 61, 2093 (1992); 10.1063/1.108317

Activation efficiency improvement in Si-implanted GaAs by $\mathrm{P}$ co-implantation

Appl. Phys. Lett. 50, 1592 (1987); 10.1063/1.97790

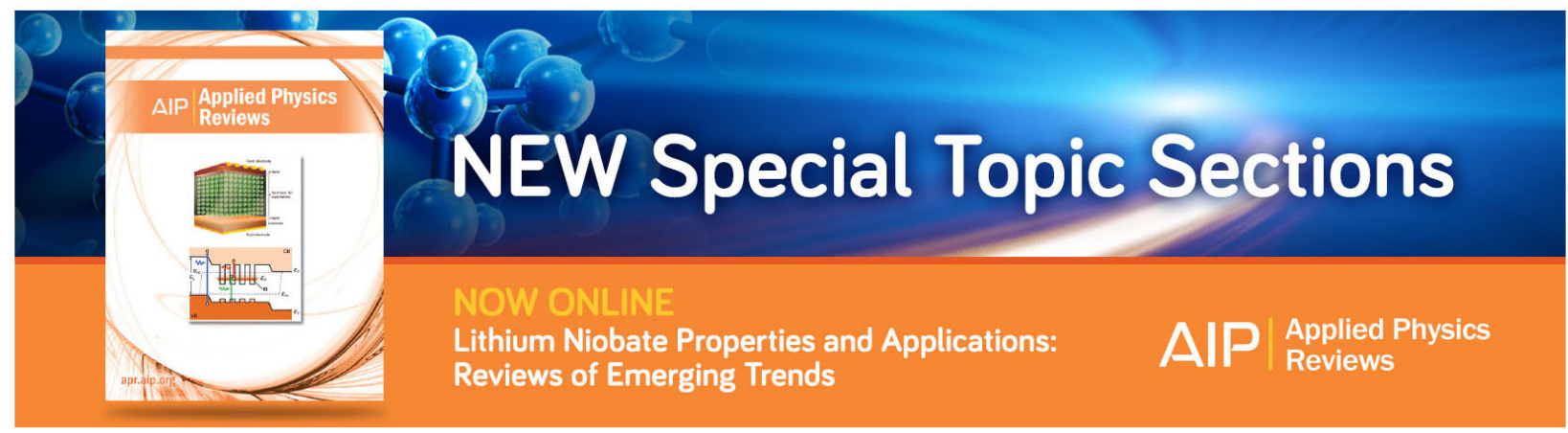




\title{
Mechanism for enhancement of electrical activation of silicon in GaAs by aluminum co-implantation
}

\author{
J.P. de Souza \\ Instituto de Física, UFRGS, 91501-970 Porto Alegre, R.S., Brazil \\ D. K. Sadana \\ Thomas J. Watson Research Center. IBM. Yorktown Heights, New York 10598
}

(Received 2 June 1993; accepted for publication 24 September 1993)

\begin{abstract}
A pronounced enhancement in the electrical activation of implanted $\mathrm{Si}$ in GaAs is demonstrated by co-implantation of $\mathrm{Al}$. The maximum enhancement $(\times 2)$ occurs when the Si distribution is shallow, there is a separation between the $\mathrm{Si}$ and $\mathrm{Al}$ distributions with the $\mathrm{Al}$ being deeper, the $\mathrm{Si}$ and $\mathrm{Al}$ are implanted at doses of $\leqslant 1 \times 10^{13} \mathrm{~cm}^{-2}$, and subsequent annealing of the co-implanted $\mathrm{GaAs}$ is performed under capless or proximity cap conditions. A model considering gettering of the oxygen present in the bulk Czochralski-grown GaAs to the implanted $\mathrm{Al}$ is invoked to explain the observed activation enhancement.
\end{abstract}

Only a fraction of implanted $n$ dopants is electrically active in GaAs even after the most optimized annealing. ${ }^{1}$ Co-implantation of $n$ dopants which occupy Ga sites (e.g., $\mathrm{Si}$ ) with a column $\mathrm{V}$ element (e.g., P) and those which occupy As sites with column III impurity (e.g., $\mathrm{Ga}$ ) has been reported to enhance the dopant activation in $\mathrm{GaAs}^{2-8}$ It was previously shown that $\mathrm{Al}$ co-implantation with $n$ dopants followed by capless rapid thermal annealing (RTA) enhances the electrical activation of these dopants in GaAs. ${ }^{9}$ The maximum carrier enhancement due to $\mathrm{Al}$ co-implantation occurs at $n$-dopant doses typically used for $n$ channels in GaAs metal-semiconductor field-effecttransistors (MESFETs) (i.e., $<1 \times 10^{13} \mathrm{~cm}^{-2}$ ).

The effect of $\mathrm{Al}$ co-implantation (at $160 \mathrm{keV}$ ) on the $\mathrm{Si}$ activation and on Hall mobility in the $\mathrm{Al}$ dose range of $1.5 \times 10^{11}-4.5 \times 10^{13} \mathrm{~cm}^{-2}$ has been discussed earlier. ${ }^{9}$ The $\mathrm{Si}$ activation increases initially with the $\mathrm{Al}$ dose and the maximum carrier enhancement occurs at an $\mathrm{Al}$ dose of $4.5 \times 10^{12} \mathrm{~cm}^{-2}$. The Si activation and carrier mobility begin to deteriorate at higher $\mathrm{Al}$ doses. At an $\mathrm{Al}$ dose of $4.5 \times 10^{13} \mathrm{~cm}^{-2}$ the Si was mostly deactivated, which is in agreement with the published data of Farley and Streetman. 6

In this letter the activation enhancement of implanted $\mathrm{Si}$ has been studied systematically as a function of $\mathrm{Al}^{+}$ energy. Due to lack of space the electrical data from only those $\mathrm{Al}$ doses is included which resulted in the maximum carrier enhancement. It is shown that the position of the $\mathrm{Al}$ profile with respect to the implanted $\mathrm{Si}$ profile determines where the electrical activation enhancement occurs spatially in the Si implanted region. Control experiments with dual $\mathrm{Al}$ and $\mathrm{O}$ implant indicate that $\mathrm{Al}$ can strongly getter oxygen present in the implanted $\mathrm{GaAs}$ substrate. The role of oxygen gettering in electrical activation enhancement is further confirmed with a $\mathrm{Mg}$ co-implant since like $\mathrm{Al}, \mathrm{Mg}$ also has a strong bond with $\mathrm{O}$. A phenomenological model which explains the observed activation behavior is proposed.

Semi-insulating CZ grown LEC (100) GaAs wafers were either implanted with ${ }^{29} \mathrm{Si}^{+}$only $\left(30 \mathrm{keV}, 6.0 \times 10^{12}\right.$ $\mathrm{cm}^{-2}$ ) (control sample) or were dual implanted with $\mathrm{Al}^{+}$ at energies of 30 (sample A), 160 (sample B), and $450 \mathrm{keV}$ (sample C) with doses of $1.5,4.5$, and $10 \times 10^{12} \mathrm{~cm}^{-2}$, respectively.

The implanted wafers subsequently underwent RTA with either a Si-proximity cap or with a conventional plasma enhanced chemical vapor deposited (PECVD) $\mathrm{Si}_{x} \mathrm{~N}_{y}$ cap. The Si-proximity RTA will be referred to as capless RTA from here on in the text. The electrical characterization of the annealed samples was performed by $\mathrm{CV}$ and Hall measurements. Atomic profiles of $\mathrm{Si}, \mathrm{Al}$, and $\mathrm{O}$ on a selected number of samples were obtained by secondary ion mass spectrometry (SIMS).

Figure 1 shows atomic profiles of $\mathrm{Si}$ and $\mathrm{Al}$ from samples $\mathrm{B}$ and $\mathrm{C}$ after capless RTA at $850^{\circ} \mathrm{C}$ for $10 \mathrm{~s}$ (the as-implanted and annealed profiles of $\mathrm{Al}$ and $\mathrm{Si}$ were indistinguishable from each other).

Carrier concentration profiles (CV) of the control sample and those of samples $\mathrm{C}$ after capless RTA at $850^{\circ} \mathrm{C} / 10 \mathrm{~s}$ are shown in Fig. 2 [curves (i)-(iv)], respectively. In sample $\mathrm{A}$ where the $\mathrm{Al}$ and $\mathrm{Si}$ depth profile are spatially coincident the $\mathrm{Si}$ activation is enhanced primarily in the tail region [compare curves (i) and (ii)]. However, the $\mathrm{Si}$ activation remains practically unaffected in the peak region in sample $\mathrm{A}$. When the $\mathrm{Al}$ profiles were deeper than

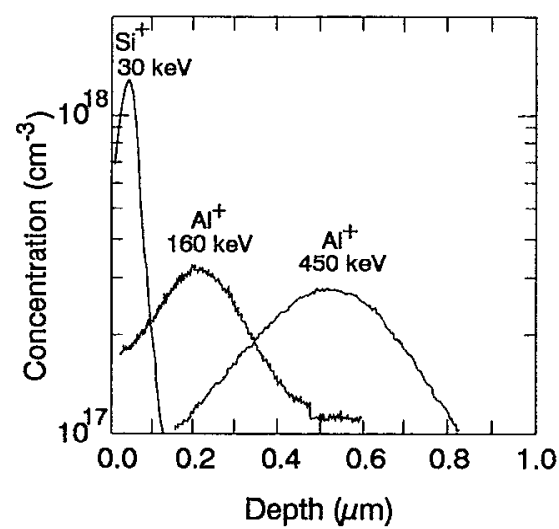

FIG. 1. Atomic profiles (SIMS) of implanted ${ }^{29} \mathrm{Si}$ and Al from samples $\mathrm{B}$ and $\mathrm{C}$ after capless annealing at $850^{\circ} \mathrm{C}$ for $10 \mathrm{~s}$. 


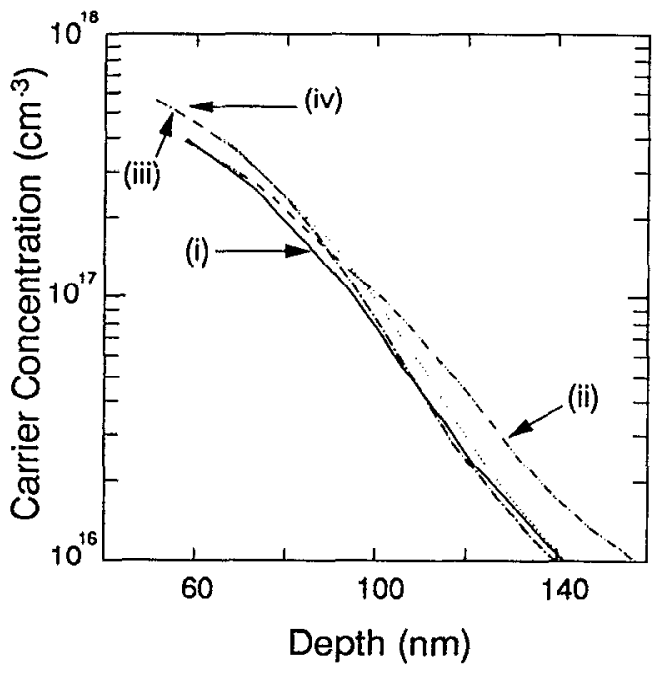

FIG. 2. Carrier concentration profiles (CV) from the sample implanted only with $\mathrm{Si}$ [control sample, curve (i)], from the sample co-implanted with Al profiles matching $\mathrm{Si}$ and [sample $\mathrm{A}$, curve (ii)], from the samples co-implanted with Al at $160 \mathrm{keV}$ [sample B, curve (iii)] and at $450 \mathrm{keV}$ [sample C, curve (iv)]. The samples were capless annealed at $850^{\circ} \mathrm{C}$ for $10 \mathrm{~s}$.

the Si profile (samples B and C) a pronounced enhancement in the carrier concentration occurred in the nearsurface region $(<0.1 \mu \mathrm{m})$. In the tail region, however, there is no measurable enhancement [compare curves (iii) and (iv) with curve (i) in Fig. 2].

The effect of a PECVD $\mathrm{Si}_{x} \mathrm{~N}_{y}$ cap on the elcetrical activation of the co-implanted samples was drastic. In contrast to the pronounced activation enhancement after capless anneal, a pronounced reduction $(\times 3-\times 4)$ occurred in the carrier density of sample B after capped RTA at $850^{\circ} \mathrm{C} / 10 \mathrm{~s}$. The Si activation continued to deteriorate as the annealing time was increased for the capped sample. For example, furnace annealing of capped samples at $840^{\circ} \mathrm{C}$ for $20 \mathrm{~min}$ converted the samples from $n$ to $p$-type with sheet carrier densities down to $<9 \times 10^{11} \mathrm{~cm}^{-2}$.

To explain the carrier enhancement in Fig. 2 we propose a model which invokes gettering of the oxygen in the starting GaAs substrate by the co-implanted Al during the activation anneal. Depending on the manufacturer, the oxygen content in a CZ-grown GaAs can be up to $2 \times 10^{17}$ $\mathrm{cm}^{-3}$. It is believed that the oxygen gettering occurs due to its strong chemical affinity for Al. The oxygen migration towards the implanted $\mathrm{Al}$ is probably facilitated by the cumulative damage created by the dopant and $\mathrm{Al}$ implants. Since $O$ is known to act as a deep double electron trap and compensates $n$ dopants in $\mathrm{GaAs},{ }^{10}$ the depletion of $\mathrm{O}$ atoms in the $n$-dopant implanted region should enhance the dopant activation. In addition, the $O$ gettering should liberate the dopants from dopant-O complexes and this should further enhance the dopant activation.

In order to determine whether Al-O gettering can indeed occur in GaAs the following control experiment was conducted. ${ }^{18} \mathrm{O}^{+}$and $\mathrm{Al}^{+}$were co-implanted with a dose of $1.0 \times 10^{13} \mathrm{~cm}^{-2}$ each at energies of 67 and $200 \mathrm{keV}$, respectively, into the GaAs substrates obtained from the same boule as those used for dopant implants. The energies

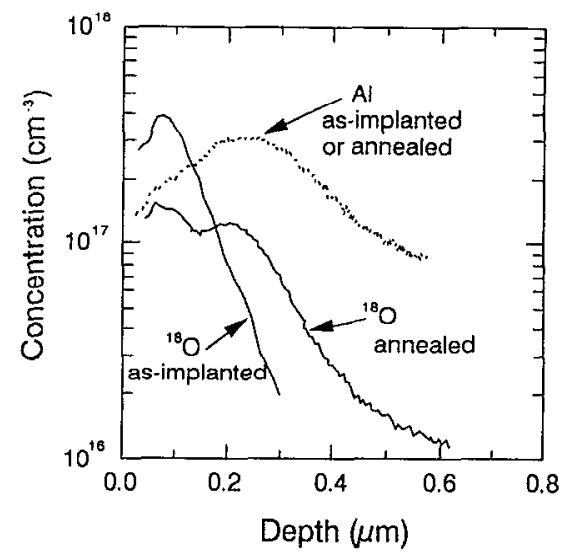

FIG. 3. Atomic profiles (SIMS) of implanted ${ }^{18} \mathrm{O}\left(1.0 \times 10^{13} \mathrm{~cm}^{-2}\right.$ at 67 $\mathrm{keV})$ and of $\mathrm{Al}\left(1.0 \times 10^{13} \mathrm{~cm}^{-2}\right.$ at $\left.200 \mathrm{keV}\right)$ before and after capless RTA at $850^{\circ} \mathrm{C}$ for $10 \mathrm{~s}$.

of $\mathrm{Al}^{+}$and $\mathrm{O}^{+}$were chosen to obtain a spatial separation between these elements so that their redistributions after the annealing could be observed. The samples subsequently underwent capless RTA at $850{ }^{\circ} \mathrm{C} / 10 \mathrm{~s}$. The ${ }^{18} \mathrm{O}$ isotope was used to improve SIMS sensitivity for oxygen detection. A pronounced redistribution of the ${ }^{18} \mathrm{O}$ in the $\mathrm{Al} / \mathrm{O} \mathrm{co}-$ implanted sample occurs after RTA (Fig. 3). The initial nearly Gaussian distribution of as-implanted ${ }^{18} \mathrm{O}$ converts into a bimodal distribution after the RTA. The Al does not show any significant redistribution during the RTA. The first peak of ${ }^{18} \mathrm{O}$ is located approximately at a depth corresponding to the mean projected range of the ${ }^{18} \mathrm{O}$ implanted profile and the second one located in the $\mathrm{Al}$ implanted region. These data (Fig. 3) clearly support the $O$ gettering theory. The effect of the $\mathrm{Al}$ is expected to be most pronounced at doses where the proportion of the background $\left(<1 \times 10^{17} \mathrm{~cm}^{-3}\right)$ oxygen relative to implanted dose is significant, i.e., in the low dose regime $\left(<1 \times 10^{13}\right.$ $\mathrm{cm}^{-2}$ ).

In order to further test the $O$ gettering model additional experiments where $\mathrm{Al}$ was replaced by $\mathrm{Mg}$ were conducted. It should be noted that the $\mathrm{Mg}-\mathrm{O}$ bond (3.4 $\mathrm{eV})^{11}$ is almost as strong as the $\mathrm{Al}-\mathrm{O}$ bond $(5.0 \mathrm{eV}) .^{11}$ The $\mathrm{Mg}^{+}$implanted sample $\left(1.5 \times 10^{12} \mathrm{~cm}^{-2}\right.$ at $\left.160 \mathrm{keV}\right)$ was submitted to a capless RTA at $850^{\circ} \mathrm{C} / 10 \mathrm{~s}$ prior to the $\mathrm{Si}$ implantation. After the $\mathrm{Si}^{+}$implantation a second capless RTA at $850^{\circ} \mathrm{C} / 10 \mathrm{~s}$ was performed in the coimplanted sample. Figure 4 shows carrier profiles of the control and $\mathrm{Mg}$ co-implanted samples. Since $\mathrm{Mg}$ is a $p$-type dopant it creates a buried $p$ layer in GaAs, which explains the observed compensation in the tail region. However, the enhancement of in the $\mathrm{Si}$ activation in the near-surface region is consistent with the oxygen gettering model proposed above.

Now we explain the spatial dependence of the Si activation on the $\mathrm{Al}^{+}$energy. If it is assumed that $\mathrm{O}$ tracks the $\mathrm{Al}$, the tail region of the Si profile will have reduced the $\mathrm{O}$ concentration in sample A. Consequently, enhanced Si activation in the tail region is expected [Fig. 2, curve (ii)]. On the other hand, in samples $B$ and $C$ where the $\mathrm{Al}$ 


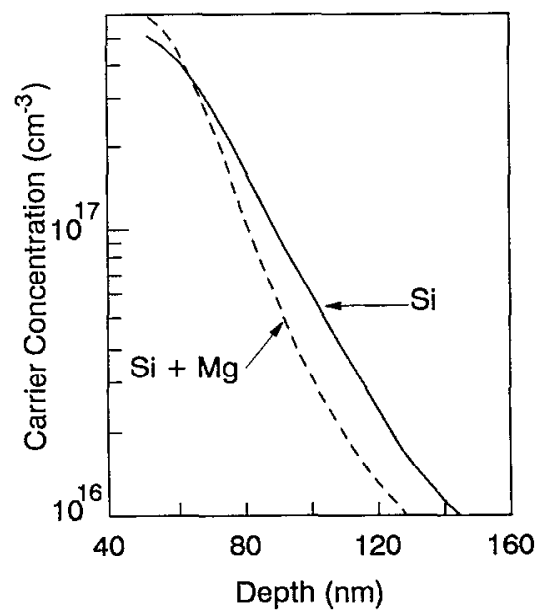

FIG. 4. Carrier concentration profiles (CV) from a sample implanted only with $\mathrm{Si}$ (control sample) and from a sample co-implanted with $\mathrm{Mg}$ $\left(1.5 \times 10^{12} \mathrm{~cm}^{-2}\right.$ at $\left.160 \mathrm{keV}\right)$ after capless RTA at $850^{\circ} \mathrm{C}$ for $10 \mathrm{~s}$.

profiles are deep the $O$ is gettered away from the peak region of the $\mathrm{Si}$ profile, resulting in higher electrical activation there.

It is believed that the deterioration of the $\mathrm{Si}$ activation in the capped annealed samples is related to the $\mathrm{H}$ diffusion from the cap during the anneal. ${ }^{12}$ Perhaps the $\mathrm{H}$ from the cap decreases the $\mathrm{O}$ gettering efficiency of the $\mathrm{Al}$ due to $\mathrm{Al}-\mathbf{H}$ interaction.

It is conceivable that point defects are also playing an important role in determining the $\mathrm{Si}$ activation in coimplanted samples. However, the observed activation enhancement can be directly correlated with the $\mathrm{O}$ movement.

${ }^{1}$ S. J. Pearton, Solid State Phenorn. 1\&2, 247 (1988).

${ }^{2}$ B. J. Sealy, E. C. Bell, R. K. Surridge, K. G. Stephens, T. Ambridge, and R. Heckingbottom, Inst. Phys. Conf. Ser. 28, 75 (1976).

${ }^{3}$ T. Inada, S. Kato, T. Ohkubo, and T. Hara, Radiat. Err. 48, 91 (1980).

${ }^{4}$ Y. S. Park, Y. K. Yeo, and F. L. Pedrotti, Nucl. Instrum. Methods $182 / 183,617$ (1981).

${ }^{5}$ H. Kräutle, Nucl. Instrum. Methods 182/183, 625 (1981).

${ }^{6}$ C. W. Farley, T. S. Kim, and B. G. Streetman, J. Electron. Mater. 16, 79 (1987)

${ }^{7}$ F. Hyuga, H. Yamazaki, K. Watanabe, and J. Osaka, Appl. Phys. Lett. 50, 1592 (1987).

${ }^{8}$ G. Marrakchi, A. Laugier, G. Guillot, S. Alaya, and H. Maaref, Appl. Phys. Lett. 59, 923 (1991).

${ }^{9} \mathrm{~J}$. P. de Souza and D. K. Sadana, in Advanced III-V Compound Semiconductors Growth, Processing and Devices, edited by S. J. Pearton, D. K. Sadana, and J. M. Zavada (Materials Research Society, Pittsburgh, 1992), Vol. 240, p. 887.

${ }^{10}$ P. N. Favennec, J. Appl. Phys. 47, 2532 (1976).

"C. T. Lynch, in Materials Science: General Properties (CRC, Cleveland, OH, 1974), p. 76.

${ }^{12}$ J. P. de Souza, D. K. Sadana, H. Baratte, and F. Cardone, Appl. Phys. Lett. 57, 1129 (1990). 